\title{
Charge transport and thermal properties of polyindole, polycarbazole and their derivatives
}

\author{
P. Syed Abthagir, R. Saraswathi* \\ Department of Materials Science, Madurai Kamaraj University, Madurai 625021, Tamil Nadu, India
}

Received 22 November 2003; received in revised form 14 April 2004; accepted 15 April 2004

Available online 25 June 2004

\begin{abstract}
The time and temperature dependences of conductivity of four polymers namely polyindole, polyindole-5-carboxylic acid, polycarbazole, and poly $(N$-vinylcarbazole) are analysed to understand the aging process and conduction mechanism. The polymers are prepared electrochemically. The conductivity data obtained over a temperature range are fitted to Arrhenius and Mott equations. The thermal degradation of both doped and dedoped samples of the four polymers in air and $\mathrm{N}_{2}$ atmosphere has been followed using thermogravimetric (TG) and differential thermal analysis (DTA). The thermal activation energies are evaluated by Horowitz and Metzger method.
\end{abstract}

(C) 2004 Elsevier B.V. All rights reserved.

Keywords: Polyindole; Polyindole-5-carboxylic acid; Polycarbazole; Poly( $N$-vinylcarbazole); Mott model; Thermal stability; Activation energy

\section{Introduction}

A milestone in the history of conjugated polymers has been the single-step electrochemical synthesis of more stable polyhetrocycles $[1,2]$. Among them, polypyrrole, polythiophene and their substituted derivatives have received a great deal of attention because of their good electrical properties, environmental stability and ease of synthesis [3,4]. A number of other heterocyclic polymers namely polyindole, polycarbazole, polyfuran, polyisothianapthene, polybithiophene and polyphenazine are also electrically conducting and continue to be developed and studied [5-10]. This paper is aimed at presenting a more systematic report on the charge transport mechanism and the thermal degradation properties of the four polymers, viz. polyindole, polyindole-5-carboxylic acid, polycarbazole and poly( $N$-vinylcarbazole $)$.

\section{Experimental}

Indole (SRL) and carbazole (Merck) were crystallized from methanol. $N$-Vinylcarbazole (Aldrich) and

\footnotetext{
* Corresponding author. Fax: +91 4522459181.

E-mail address: saraswathir@yahoo.com (R. Saraswathi).
}

indole-5-carboxylicacid (Acros) were used as received. The polymers were synthesized electrochemically using the following conditions. Polyindole is obtained from: (i) $0.1 \mathrm{M}$ indole and $0.1 \mathrm{M} \mathrm{LiClO}_{4}$ in acetonitrile; and (ii) $0.2 \mathrm{M}$ indole and $0.2 \mathrm{M} \mathrm{Bu} \mathrm{Bu}_{4} \mathrm{NBF}_{4}$ in acetonitrile. Polyindole-5-carboxylicacid was electrodeposited on a platinum substrate from acetonitrile containing: (i) $20 \mathrm{mM}$ monomer and $0.1 \mathrm{M} \mathrm{LiClO}_{4}$; and (ii) $40 \mathrm{mM}$ monomer and $0.1 \mathrm{M} \mathrm{Bu}_{4} \mathrm{NBF}_{4}$. A potentiostatic method $(0.8 \mathrm{~V}$ for polyindole and $1.2 \mathrm{~V}$ for polyindole-5-carboxylicacid) has been used in the above experiments. The polymer samples obtained in the presence of $\mathrm{LiClO}_{4}$ were used to study the temperature dependence of conductivity. For thermal analysis by thermogravimetric (TGA) and differential thermal analysis (DTA) techniques, the samples prepared in the presence of $\mathrm{Bu}_{4} \mathrm{NBF}_{4}$ were used. This was necessary as the perchlorate doped polymer might be explosive and heating it to high temperature was not desirable. For preparing polycarbazole and poly $(N$-vinylcarbazole $)$ by elcectropolymerization, the electrolyte solution contained $5 \times 10^{-3} \mathrm{M}$ monomer in $75 \mathrm{vol} . \%$ methanol $+25 \mathrm{vol} \%$ aqueous $5 \mathrm{M}$ perchloric acid or fluoboric acid. The films were deposited potentiostatically on a Pt electrode, by applying $1.05 \mathrm{~V}$ for polycarbazole and $1.2 \mathrm{~V}$ for poly $(N$-vinylcarbazole). The reference electrode was $\mathrm{Ag}$, $\mathrm{AgCl} / \mathrm{Cl}^{-}$(satd). Dedoped samples of the polymers were 
obtained by treatment with $0.1 \mathrm{M}$ ammonium hydroxide for about $6 \mathrm{~h}$.

A scanning potentiostat (PAR Model 263A) was used for electrochemical experiments. The powder samples were pressed into pellets using a Perkin-Elmer hydraulic press by applying a pressure of 6 tonnes. The resistance of the pellets were measured by two probe method using a digital multimeter (Model 195 A, Keithley Instruments Ltd., USA). A liquid nitrogen bath cryostat (Model DP-422, Scientific Solution, Mumbai, India) was used for low temperature resistance measurements. The cryostat consisted of a sample chamber surrounded by vacuum isolation chamber. The sample holder was fitted with a platinum temperature sensor (Pt-100) and a $25 \Omega$ heater. GE varnish (which has good thermal conductivity at low temperature) was used for mounting the sample. A mixture of toluene-ethanol (1:1) was used as the thinner. A home-made variable temperature oven was used for the resistance measurements from ambient to higher temperature and also for aging studies at $423 \mathrm{~K}$. The thermograms were recorded at a heating rate of $10 \mathrm{~K} \mathrm{~min}^{-1}$ using a thermal analyzer (NETZSCH-Geratebau GmbH STA 409 PC).

\section{Results and discussion}

\subsection{Time and temperature effects on conductivity}

At first, the variation of conductivity of the four polymers as a function of time is monitored. The measurement of time dependence of conductivity is significant for two reasons: (i) the temperature dependence of conductivity can be measured in a reliable way only when time-dependent changes are slow on the time scale employed during temperature changes; and (ii) the structural changes that may occur on annealing the sample at constant temperatures may be understood.

The annealing of the four polymers at $373 \mathrm{~K}$ did not lead to a drastic change in conductivity even after $50 \mathrm{~h}$ of standing. Hence, further aging tests were carried out at $423 \mathrm{~K}$. Fig. 1 shows the variation of resistance with time at

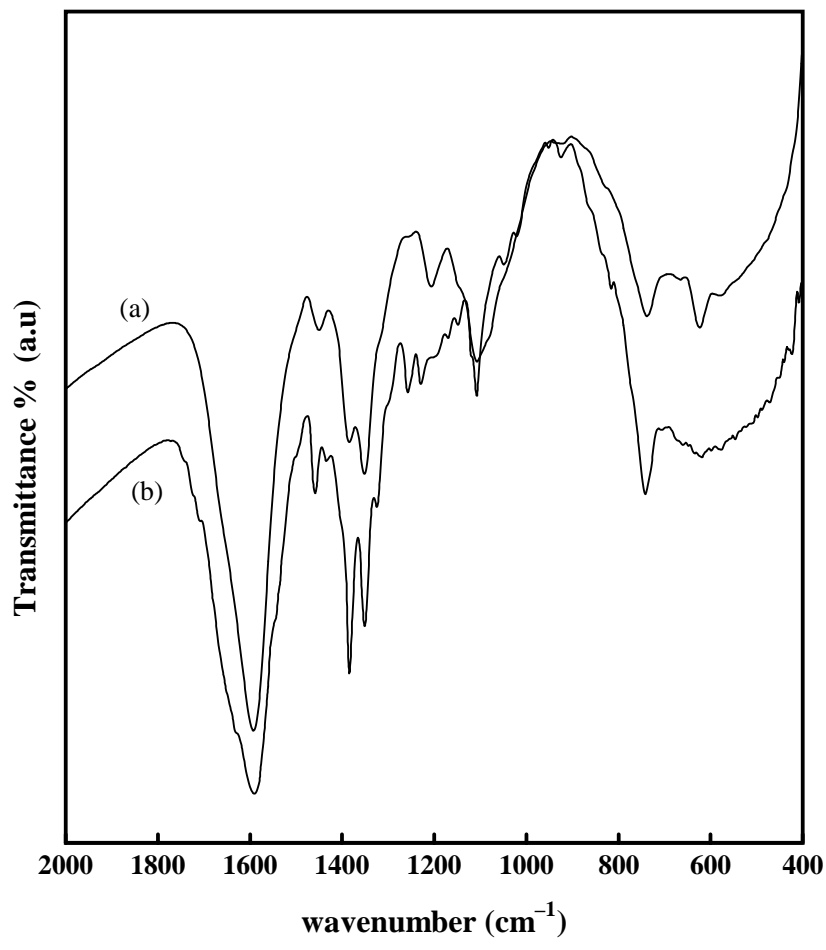

Fig. 2. FT-IR of polyindole: (a) as-grown sample; and (b) aged sample.

an annealing temperature of $423 \mathrm{~K}$ for perchlorate doped polyindole and polycarbazole along with the self-doped polyindole-5-carboxylic acid. The curves for polyindole and polycarbazole show two distinct steps of loss in conductivity. A slow and gradual change in conductance occurs up to about $185 \mathrm{~h}$ and thereafter a rapid increase is observed for polyindole. For polycarbazole, there is little change in resistance at this temperature up to about $30 \mathrm{~h}$. Thereafter the resistance shows a steady increase with time (Fig. 1c). The initial loss in conductivity corresponding to the first step is due to the elimination of the dopant as judged from the IR spectrum of the aged sample not showing the characteristic bands for the perchlorate ion at 1090 and $630 \mathrm{~cm}^{-1}$ (Fig. 2). The second step is inferred to be due to the structural

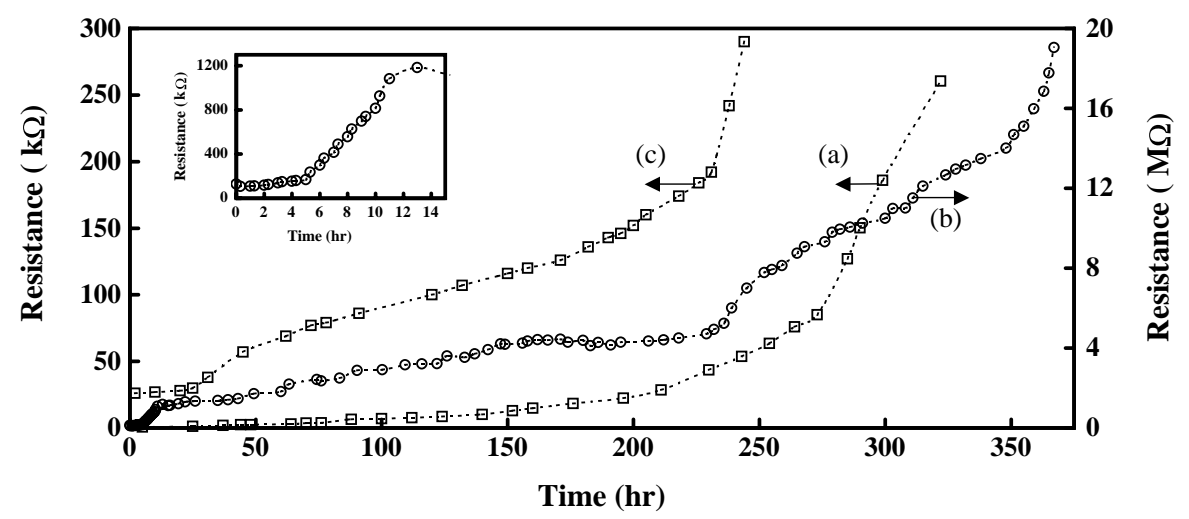

Fig. 1. Change in resistance with aging time at $423 \mathrm{~K}$ for: (a) polyindole-perchlorate; (b) polyindole-5-carboxylic acid; and (c) polycarbazole-perchlorate. Inset: resistance data obtained for polyindole-5-carboxylic acid on aging between 0 and $15 \mathrm{~h}$ at $423 \mathrm{~K}$. 
reorganization that may occur as a result of the loss of dopant and loss in conjugation of the polymer backbone. The resistance of polyindole-5-carboxylic acid shows a sharp increase between 5 and $13 \mathrm{~h}$ of aging at $423 \mathrm{~K}$ (inset in Fig. 1). Thereafter, the change in resistance remains gradual up to about $230 \mathrm{~h}$ at which time, the resistance increases rapidly once again (Fig. 1b). The above results indicate possible changes in the structure of the polymers and also in conduction mechanism during aging at $423 \mathrm{~K}$. In the case of poly $(N$-vinylcarbazole), the resistance $(10 \mathrm{M} \Omega)$ drastically increased to a high value which was not measurable by the instrument (Keithely 195 A Digital Multimeter, maximum $20 \mathrm{M} \Omega$ ) used in this study.

The conductivities of polyindole and polyindole-5-carboxylicacid have been measured in the range of temperature between 93 and $523 \mathrm{~K}$ (Fig. 3a and b). Polyindole-perchlorate shows a maximum conductivity of $3 \times 10^{-2} \mathrm{~S} \mathrm{~cm}^{-1}$ at $450 \mathrm{~K}$. A value of $4.5 \times 10^{-2} \mathrm{~S} \mathrm{~cm}^{-1}$ is obtained at $399 \mathrm{~K}$ for polyindole-5-carboxylic acid. The conductivities of both the polymers decrease by a factor of 4 with decreasing temperature. A significant difference in the variation of conductivity is observed at high temperature. For example above $455 \mathrm{~K}$, the variation of conductivity
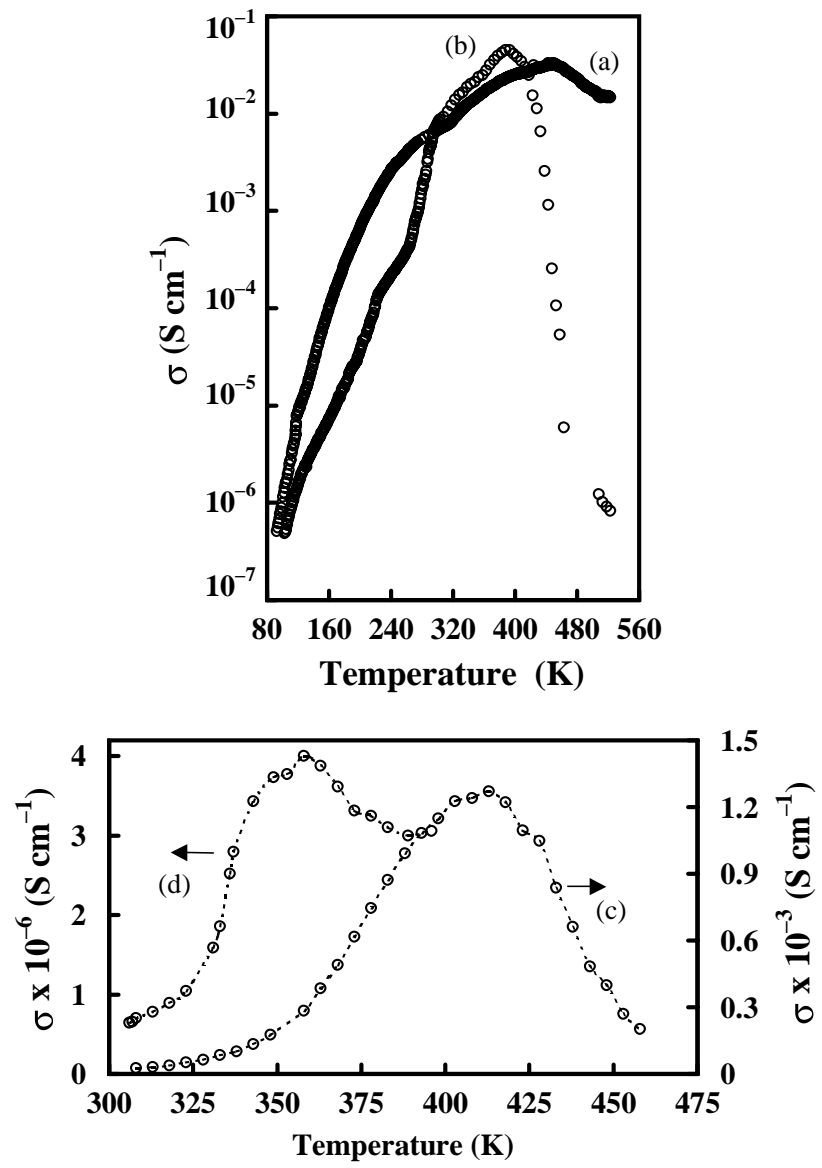

Fig. 3. Temperature dependence of electrical conductivity for: (a) polyindole; (b) polyindole-5-carboxylic acid; (c) polycarbazole; and (d) poly $(N$-vinyl carbazole). of polyindole-perchlorate is very gradual whereas in the case of self-doped polyindole-5-carboxylic acid there is a rapid decrease in conductivity between 400 and $500 \mathrm{~K}$. It is inferred that the perchlorate ions get eliminated from polyindole above $455 \mathrm{~K}$. The rapid decrease in conductivity in polyindole-5-carboxylic acid is inferred to be due to the elimination of the carboxylate ion from the polymer. Evidence for the decarboxylation has been obtained from the detailed thermogravimetric analysis which is described later.

The conductivities of the polycarbazole and poly $(N$-vinylcarbazole) are measured in the temperature range between 306 and $475 \mathrm{~K}$ (Fig. 3c and d). Low temperature measurements of conductivity could not be carried out due to the poor conductivities of both polymer samples. In the case of polycarbazole, the conductivity gradually increases with increase in temperature up to $413 \mathrm{~K}$, at which temperature a maximum value of $1.27 \times 10^{-3} \mathrm{~S} \mathrm{~cm}^{-1}$ is observed. Beyond $413 \mathrm{~K}$, the rapid decrease in conductivity occurs due to the elimination of the dopant ion from the polymer matrix. With poly $(N$-vinylcarbazole $)$, the maximum conductivity that could be observed is $4 \times 10^{-6} \mathrm{~S} \mathrm{~cm}^{-1}$ at $358 \mathrm{~K}$. In poly $(N$-vinylcarbazole $)$ the loss in conductivity due to dopant elimination occurs at $55 \mathrm{~K}$ lower than in polycarbazole.

The electrical conductivity of conducting polymers depend upon numerous factors. The nature and chemical reactivity of the dopant, the process of doping, doping level, and polymer crystallinity have been found to play a vital role in controlling the conductivity. Thus, the conduction process in polymers is a complex phenomenon. While many models have been proposed for conduction in conducting polymers, to date no single model is comprehensively accurate [11]. In varying degrees, the various models are able to account for conduction behavior within a specific temperature range or doping range or dopant type but they fail for other ranges or types or for other conducting polymers. In one case, a three-dimensional (3D) conduction model may be valid, whereas in another case, it may not be so. There have been several reports [12-15] in which the temperature dependent conductivity data of conducting polymers have been fitted to the Arrhenius equation of conductivity.

$\sigma=\sigma_{\mathrm{o}} \exp \left(-\frac{E_{\mathrm{a}}}{k T}\right)$

where $E_{\mathrm{a}}$ is the activation energy. This equation is mostly applicable near room temperature suggesting the interaction of nearest neighbouring charge carriers [16].

Another conduction model to be considered for conducting polymers, primarily because it appeared to apply to disordered semiconductors was that of Mott and co-workers [17-19]. In this model, the conductivity is treated as temperature activated hopping from center to center (variable range hopping (VRH)) and tends to zero with temperature. The lack of ordering in amorphous conducting polymers is expected to produce localized electronic states. An electron initially in a localized state can move by thermally activated 
hopping to another localized state and conduction occurs through variable range hopping of electron between these localized states. It is important that the wave functions of the two localized states should overlap enough to allow tunneling between them. The Mott model defines the relation between conductivity and temperature as below:

$\sigma=K_{\mathrm{o}} T^{-1 / 2} \exp \left[-\left(\frac{T_{\mathrm{o}}}{T}\right)^{1 / 4}\right]$

$T_{\mathrm{o}}=16 \alpha^{3} / k_{\mathrm{B}} N\left(E_{\mathrm{F}}\right)$

$K_{\mathrm{o}}=0.39\left[N\left(E_{\mathrm{F}}\right) / \alpha k_{\mathrm{B}}\right]^{1 / 2} v_{\mathrm{o}} e^{2}$

where $\alpha^{-1}$ is the decay length of the localized state; $v_{\mathrm{o}}$ a hopping attempt frequency; $N\left(E_{\mathrm{F}}\right)$ the density of the Fermi energy level; $e$ the electronic charge; $k_{\mathrm{B}}$ the Boltzmann constant; $T_{\mathrm{O}}$ the Mott characteristic temperature and $K_{\mathrm{O}}$ the Mott characteristic conductivity parameter. One usually tries to fit, temperature versus dc conductivity data to a $T^{-(1 /(n+1))}$ fit, with information on dimensionality of conduction $(n)$ then obtainable.

The Arrhenius and Mott plots of conductivity for the four polymers are shown in Figs. 4 and 5. The activation energy obtained from the slope of the Arrhenius plot for polyindole-perchlorate is $0.12 \mathrm{eV}$. The temperature dependence of conductivity for polyindole films doped with $\mathrm{BF}_{4}{ }^{-}$, $\mathrm{ClO}_{4}{ }^{-}$and $\mathrm{PF}_{6}^{-}$ions in a narrow temperature range of
123-298 K has been reported [20-22]. The reported Arrhenius $(0.4-0.6 \mathrm{eV})$ slopes are higher than the value obtained in the present study. Assuming a 3D conduction, the Mott parameters are estimated from the plot of $\ln \left(\sigma T^{1 / 2}\right)$ versus $T^{-1 / 4}$ (Fig. 4b). The value of $T_{\mathrm{o}}$ and $K_{\mathrm{o}}$ are $1.69 \times 10^{8} \mathrm{~K}$ and $9.31 \times 10^{10} \mathrm{~S} \mathrm{~cm}^{-1} \mathrm{~K}^{1 / 2}$, respectively.

The data obtained for polyindole-5-carboxylic acid did not yield good linear plots for the Arrhenius equation (Fig. 4c) and also for Mott expression if $n$ were to be assumed to be 3. Instead, the data can be fitted to a quasi 1D-variable range hopping model (Fig. 4d). Then, the Mott plot is linear in the temperature range between 103 and $378 \mathrm{~K}$. The $T_{\mathrm{o}}$ and $K_{\mathrm{O}}$ values are $6.25 \times 10^{4} \mathrm{~K}$ and $5.83 \times 10^{4} \mathrm{~S} \mathrm{~cm}^{-1} \mathrm{~K}^{1 / 2}$.

The Arrhenius and Mott plots of conductivity for polycarbazole-perchlorate are shown in Fig. 5a and b. It should be mentioned here that, the conductivity measurements have been made in the range of temperature between 305 and $460 \mathrm{~K}$ which is not enough generally to determine in detail the charge transport mechanism. It is essential to have the measurements done at low temperatures for accurate prediction of the transport properties. Nevertheless, the analysis of the data obtained above the room temperature has yielded an activation energy of $0.51 \mathrm{eV}$ for polycarbazole. In general, films with higher conductivity exhibit thermal activation behavior with a very low activation energy [23]. Therefore, the higher activation energy value of polycarbazole indicates that the intrinsic charge carriers are
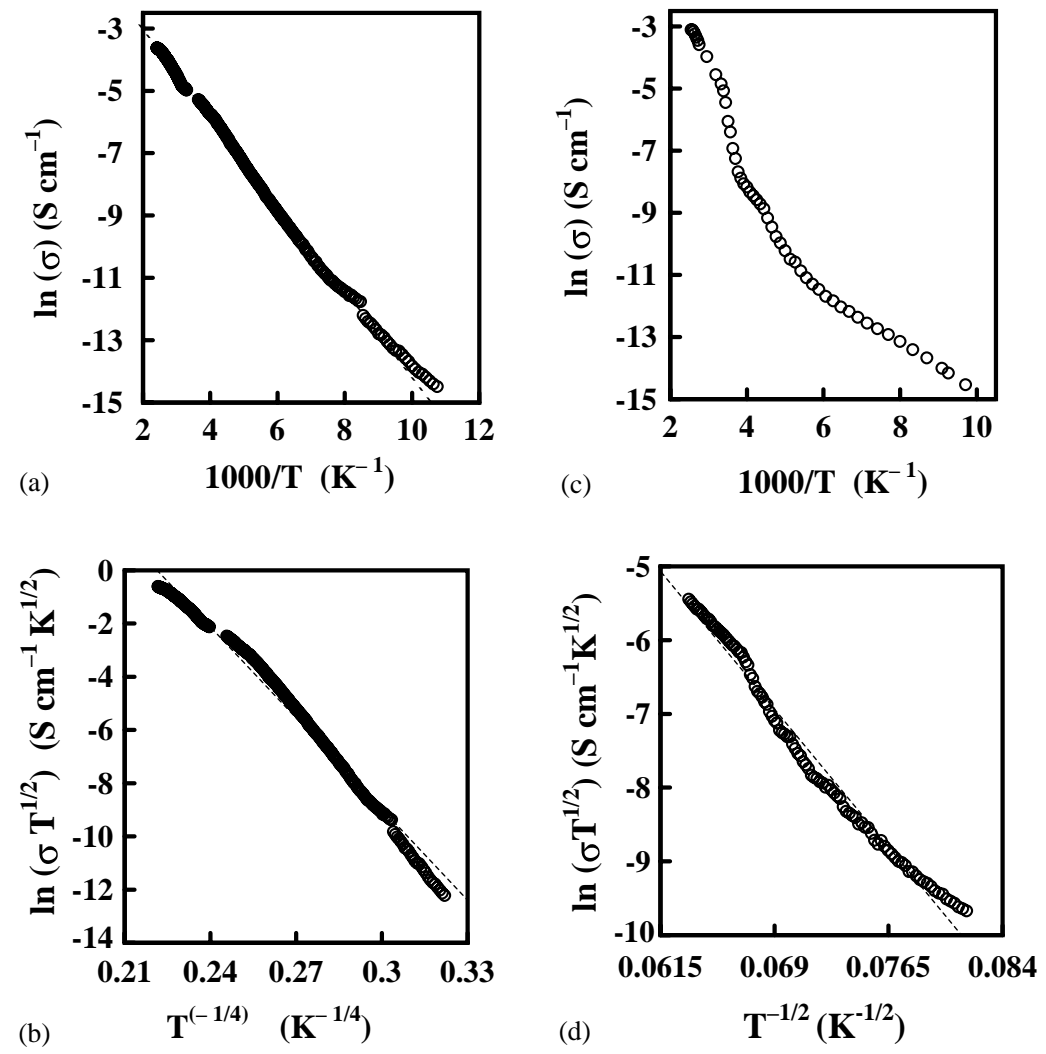

Fig. 4. Arrhenius and Mott plots of conductivity for polyindole-perchlorate (a and b) and polyindole-5-carboxylic acid (c and d). Plot b is obtained using 3D-Mott model while plot $\mathrm{d}$ is made using 1D-model. 

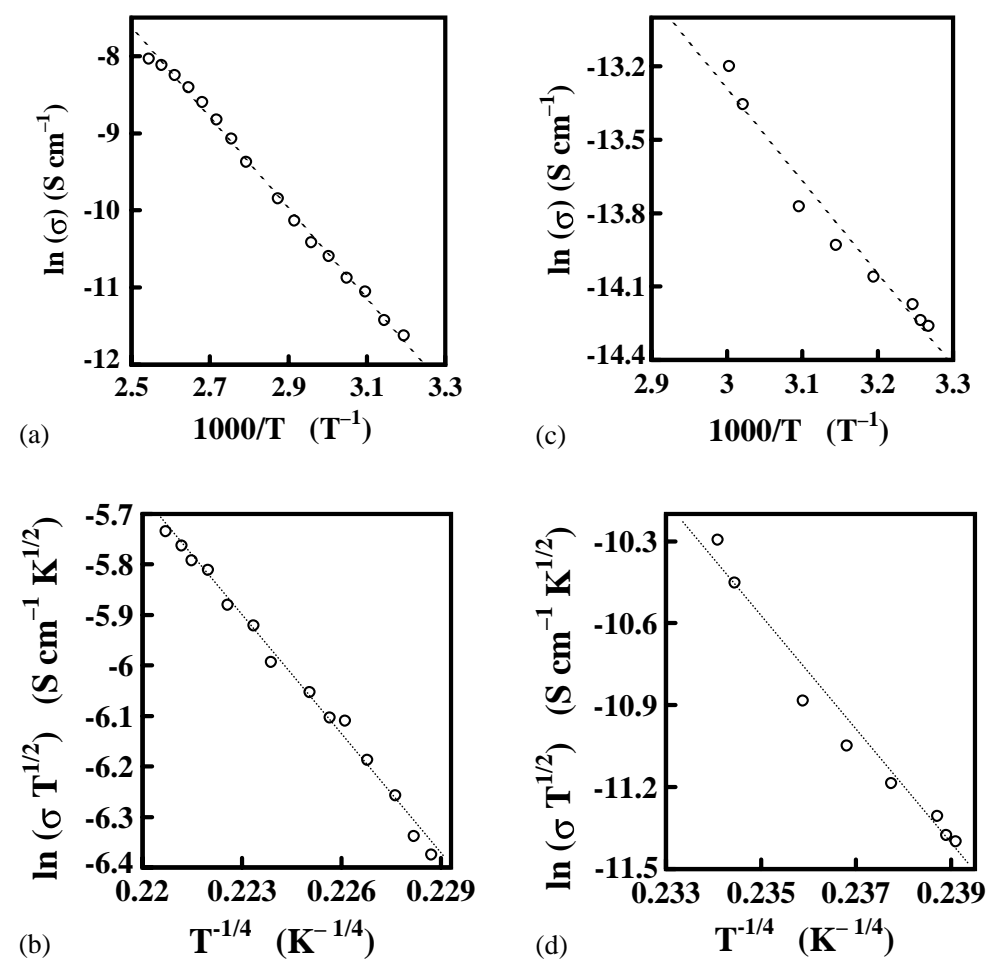

Fig. 5. Arrhenius and Mott plots of conductivity for polycarbazole-perchlorate (a and b) and poly( $N$-vinylcarbazole)-perchlorate (c and d).

less at room temperature in polycarbazole. This has led to a low conductivity of this polymer. The Mott plot of polycarbazole (Fig. 5b) gives a value of $1.35 \times 10^{6} \mathrm{~K}$ for $T_{\mathrm{o}}$ and $1.1 \times 10^{5} \mathrm{~S} \mathrm{~cm}^{-1} \mathrm{~K}^{1 / 2}$ for $K_{\mathrm{o}}$.

In the case of poly( $N$-vinylcarbazole), the Arrhenius slope is $0.34 \mathrm{eV}$. The slope and intercept of the Mott plot give very high values of $T_{\mathrm{o}}\left(1.9 \times 10^{9} \mathrm{~K}\right)$ and $K_{\mathrm{o}}$ $\left(5 \times 10^{16} \mathrm{~S} \mathrm{~cm}^{-1} \mathrm{~K}^{1 / 2}\right)$. The electrical conductivity data of poly $(N$-vinylcarbazole) seem to correlate well with the Arrhenius equation in the range of temperature studied. This possibly suggests a nearest neighbour hopping transport rather than the variable range hopping being operative in this polymer.

\subsection{Thermal stability}

Choi and co-workers [20-22] have published several reports on the physicochemical properties of polyindole doped with various counter ions. Their results on the thermogravimetric analysis indicated that the polyindole was decomposed at a higher temperature compared to polyaniline. Our earlier study also emphasized the higher thermal stability of polyindole and polycarbazole than polyaniline, polypyrrole and polythiophene [24]. There has been no systematic evaluation of thermal stability of polycarbazole and poly $(N$-vinylcarbazole $)$ in literature. Mano and Calafate [25] reported a glass transition temperature of $506 \mathrm{~K}$ for poly $(N$-vinylcarbazole) based on differential scanning calorimetry analysis. The kinetics of polymerization of carbazole was followed by isothermal thermo- gravimetric analysis [26]. Touihri et al. [27] have reported the thermal characterization of the commercially available poly $(N$-vinylcarbazole $)$ and its iodine doped powder sample. To our knowledge, there has been no report on the thermal stability of polyindole-5-carboxylic acid. The present report aims at a systematic study to obtain information on the thermal stability of the four polymers in both doped and dedoped forms in air and $\mathrm{N}_{2}$ atmosphere.

Fig. 6 shows the thermogravimetric data of polyindole doped with $\mathrm{BF}_{4}{ }^{-}$counter ions in both air and $\mathrm{N}_{2}$ atmosphere. The small weight loss of $3 \%$ observed in the TG obtained in air could be due to a loss of moisture trapped in the polymer. The dopant elimination occurs between 473 and $623 \mathrm{~K}$ with a weight loss of about $25 \%$. The backbone rupture begins after the dopant elimination which leads to a further weight loss of about $50 \%$ at $873 \mathrm{~K}$. The TG in $\mathrm{N}_{2}$ is qualitatively similar to that of the curve obtained in air but with a delayed thermal degradation. The TG curves of the dedoped sample in air and $\mathrm{N}_{2}$ atmosphere show $50 \%$ weight loss at 817 and $954 \mathrm{~K}$, respectively (Fig. 7). The DTA of the doped and dedoped samples show three prominent peaks. The first peak at $373 \mathrm{~K}$ is due to the presence of moisture in the polymer. The prominent third peak at about $750 \mathrm{~K}$ is assignable to the rupture of the polymer backbone. The second peak at about $600 \mathrm{~K}$ is attributed to a different product formed during the electropolymerization of indole. Recent literature reports indicate that the electropolymerization of indole in acetonitrile containing $\mathrm{LiClO}_{4}$ does not always lead to a single product of doped polyindole $[28,29]$. Jackowska et al. [30] have reported that three coloured compounds could be 

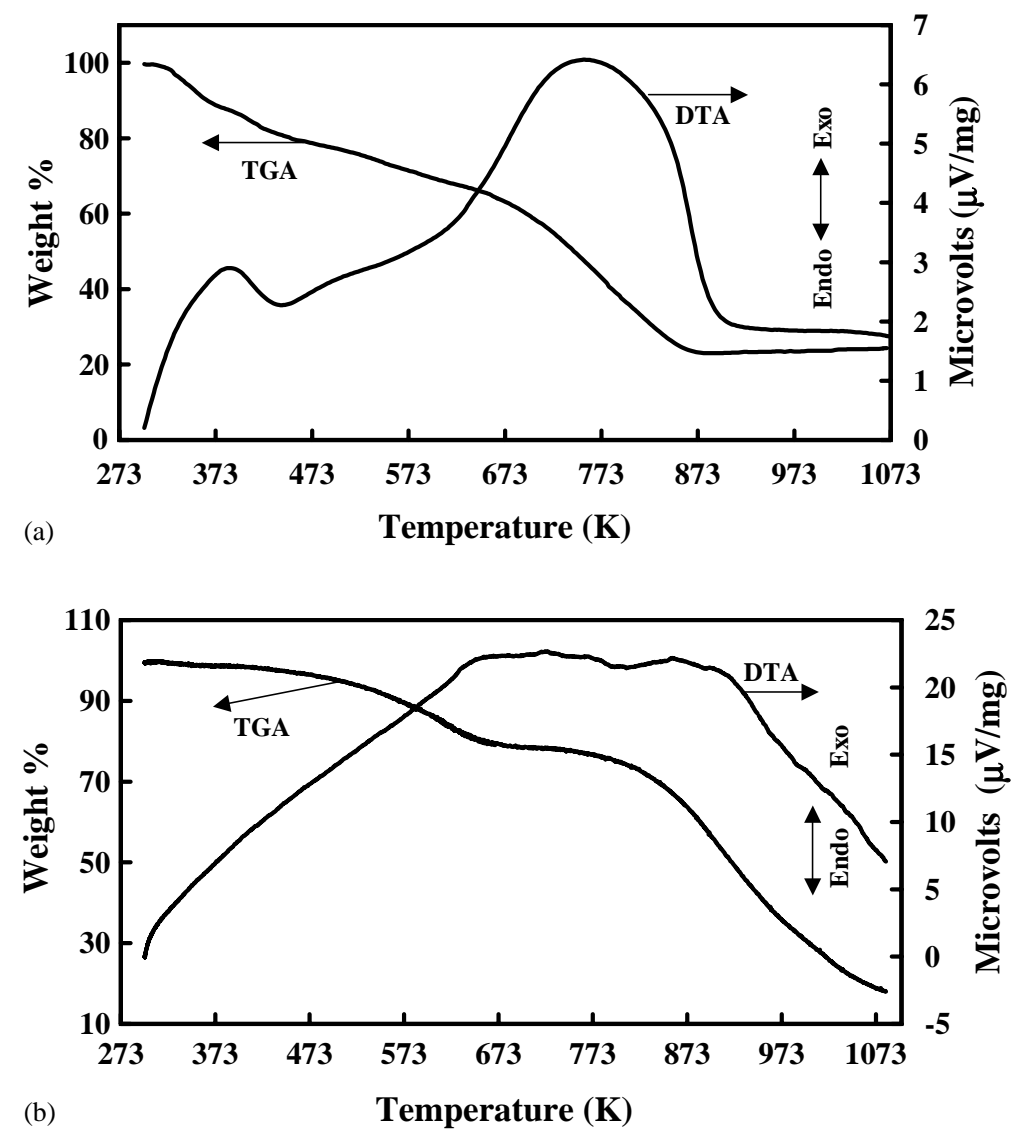

Fig. 6. TGA and DTA curves of polyindole-tetrafluoroborate in (a) air and (b) $\mathrm{N}_{2}$ atmosphere.

separated chromatographically from the electropolymerized product. The UV measurements of the solutions extracted using a microsyringe during polyindole deposition showed two absorption maxima at 375 and $425 \mathrm{~nm}$ [22]. Mackintosh and Mount [31,32] have found evidence for the formation of a trimer in addition to the polymer during the electropolymerization of indole-5-carboxylic acid in acetonitrile.

In the present study, the cyclic voltammograms of polyindole films obtained on a platinum substrate in acetonitrile containing $0.1 \mathrm{M} \mathrm{LiCIO}_{4}$ as supporting electrolyte show the presence of two electroactive species in the film (Fig. 8).
Our earlier studies have shown that the distribution of the two species depend on the synthesis conditions like indole concentration, polymerization potential and electrolyte concentration [33]. On the basis of the above data, the second peak observed in the DTA of polyindole at $623 \mathrm{~K}$ (and also polyindole-5-carboxylicacid) in the present study is assigned to the trimer formed during electropolymerization of indole.

The thermal stability of polyindole-5-carboxylic acid has also been studied both in air and $\mathrm{N}_{2}$ atmosphere (Fig. 9). No step corresponding to the elimination of the dopant is expected as polyindole-5-carboxylic acid is a self-doped

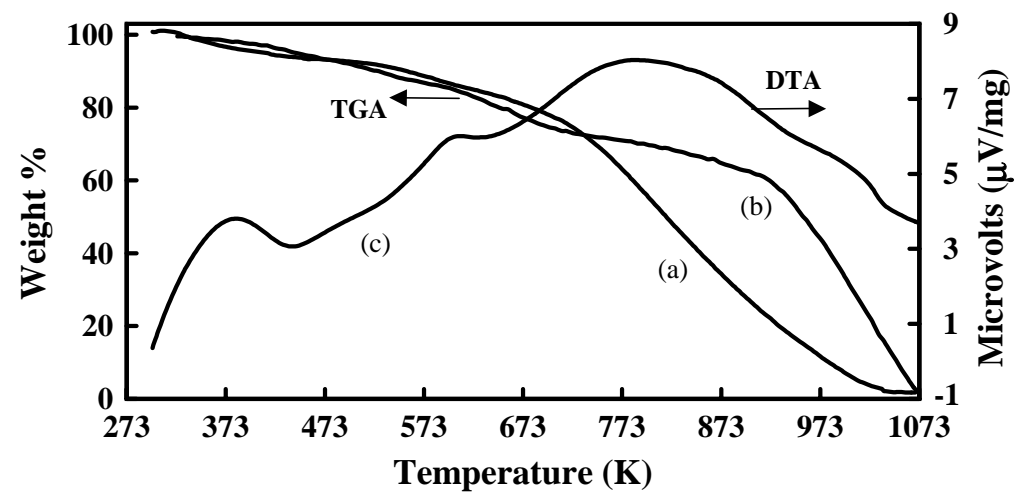

Fig. 7. TGA of dedoped polyindole in (a) air and (b) $\mathrm{N}_{2}$ atmosphere and (c) DTA dedoped polyindole in air. 


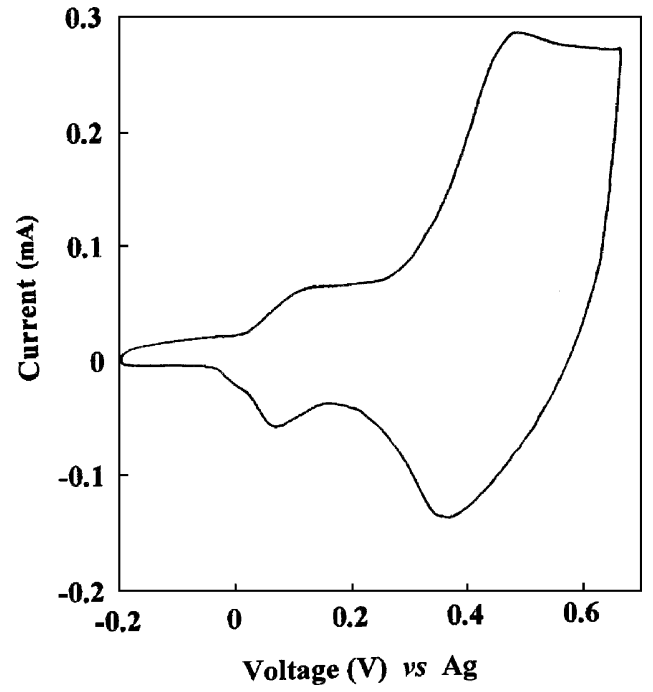

Fig. 8. Cyclic voltammogram of polyindole in acetonitrile containing $0.1 \mathrm{M} \mathrm{LiClO}_{4}$ at $50 \mathrm{mV} \mathrm{s}^{-1}$.

polymer [34]. But a weight loss is observed from $390 \mathrm{~K}$ onwards both in air and $\mathrm{N}_{2}$ atmosphere. This can be attributed to the elimination of the carboxylate ion from the polymer. This decarboxylation step is also confirmed from the TG of the monomer indole-5-carboxylic acid. It may be recalled here that this polymer loses its conductivity at temperatures between 400 and $500 \mathrm{~K}$. The loss of carboxylate ion will instantaneously eliminate the positive charges on the polymer backbone. In other words, the concentration of polarons will substantially decrease due to the gradual elimination of the carboxylate ion from the polymer. The thermal decomposition of the polymer backbone begins at about $673 \mathrm{~K}$.

Fig. 10 shows the TG and DTA curves of polycarbazole prepared from aqueous-methanolic solution containing $5 \mathrm{M}$ $\mathrm{HBF}_{4}$. The TG of the doped polymer in air (Fig. 10a) shows two distinct weight loss steps. There is a $10 \%$ decrease in weight below $423 \mathrm{~K}$. The dopant $\left(\mathrm{BF}_{4}{ }^{-}\right)$elimination begins at $473 \mathrm{~K}$ and gets completed at $673 \mathrm{~K}$ with a total weight loss of $35 \%$. The polymer decomposition begins at $723 \mathrm{~K}$. At $803 \mathrm{~K}$, there is $50 \%$ weight loss. The dedoped polycarbazole in air (Fig. 10b) shows a $10 \%$ weight loss below $723 \mathrm{~K}$ after which rapid decomposition occurs. A weight loss of $50 \%$ is observed at $933 \mathrm{~K}$. The dopant elimination in $\mathrm{N}_{2}$ (Fig. 11a) atmosphere occurs at the same temperature range (473-673 K) as observed in air. However, the polymer decomposition is delayed by $120 \mathrm{~K}$ in $\mathrm{N}_{2}$ atmosphere. The TG of the dedoped form of polycarbazole in $\mathrm{N}_{2}$ is shown in Fig. 11b. The polymer loses $50 \%$ of weight at $1020 \mathrm{~K}$. The TG and DTA data obtained for poly $(N$-vinylcarbazole) in both air and $\mathrm{N}_{2}$ atmosphere are given in Figs. 12 and 13. The decomposition of poly $(N$-vinylcarbazole $)$ occurs at a temperature $50 \mathrm{~K}$ lower than the decomposition temperature of polycarbazole in both air and $\mathrm{N}_{2}$ atmosphere. A weight
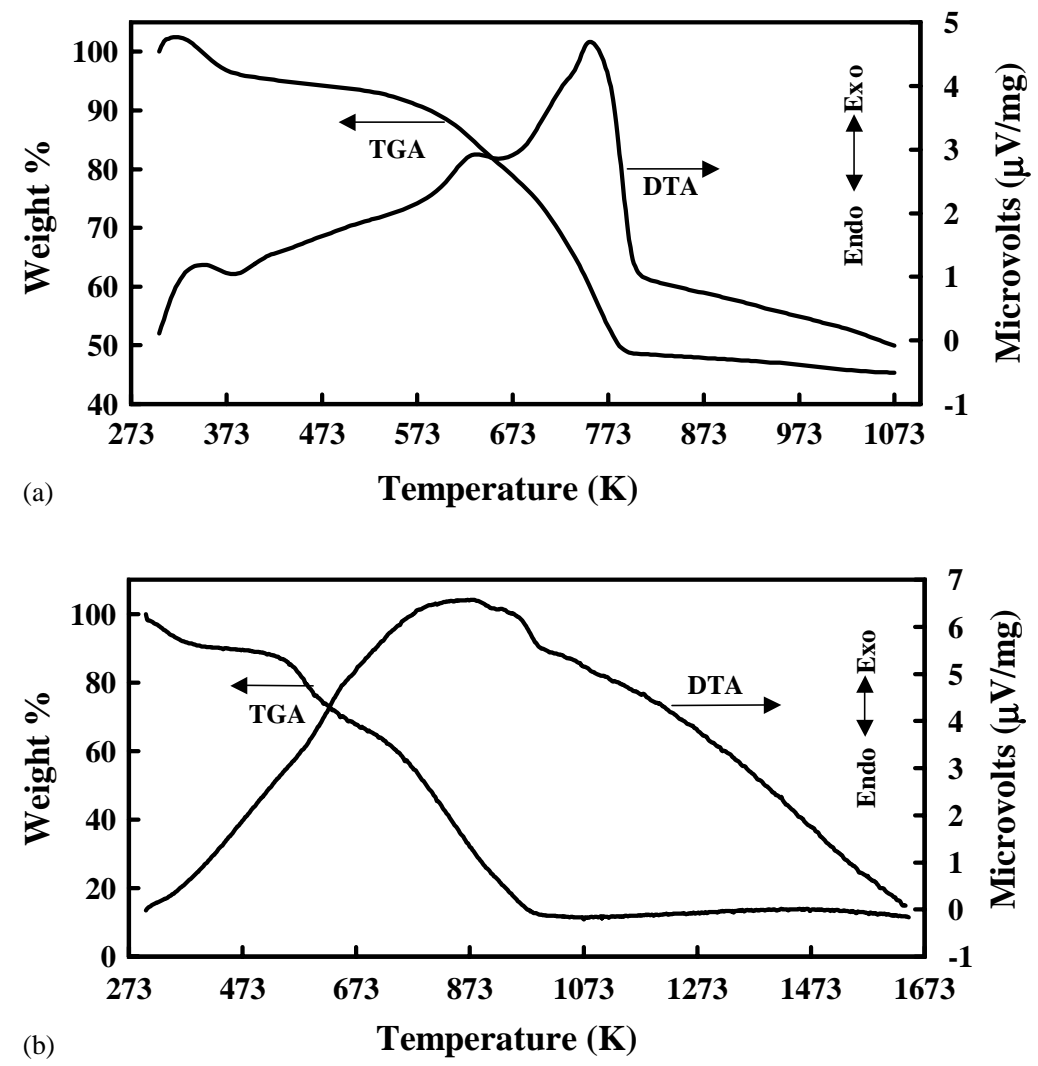

Fig. 9. TGA and DTA curves of polyindole-5-carboxylic acid in (a) air and (b) $\mathrm{N}_{2}$ atmosphere. 

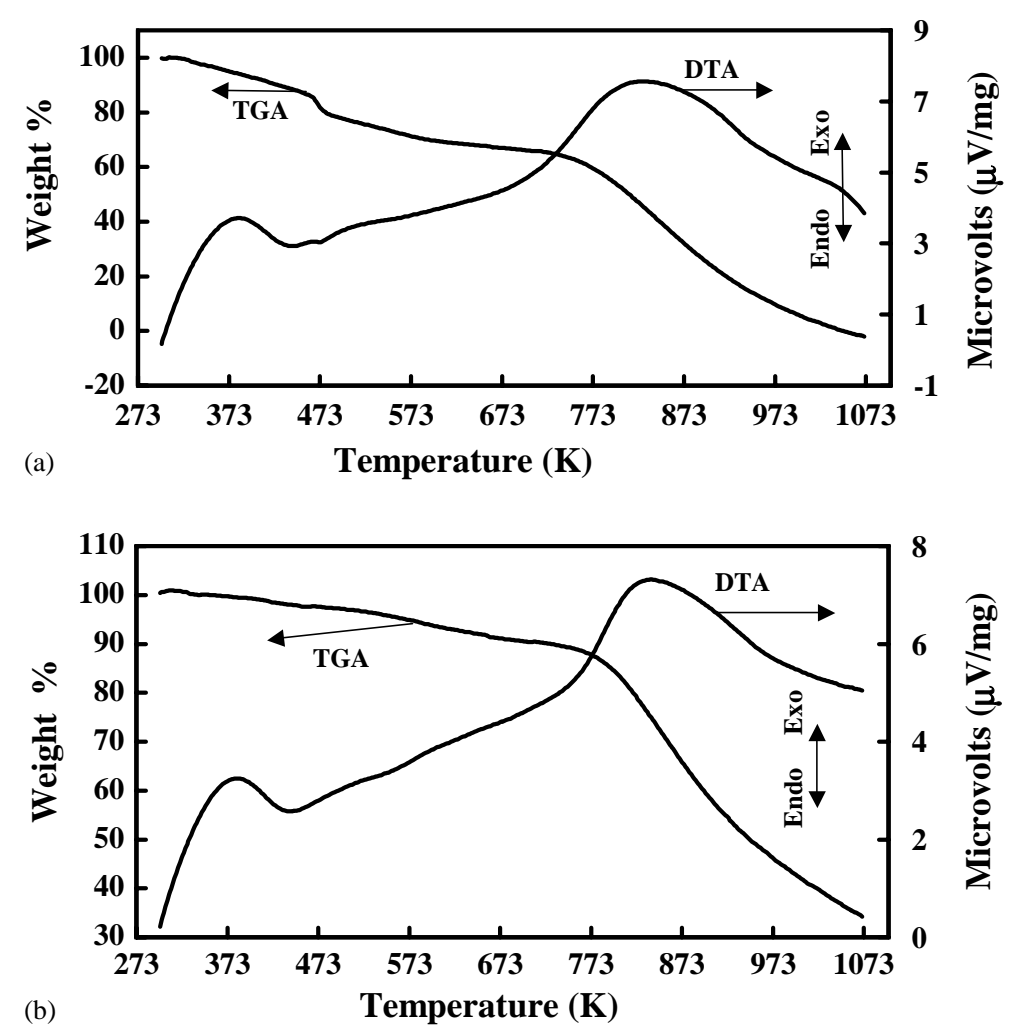

Fig. 10. TGA and DTA curves of polycarbazole (a) doped and (b) dedoped in air.

loss of $50 \%$ is observed at $793 \mathrm{~K}$ in air and at $893 \mathrm{~K}$ in $\mathrm{N}_{2}$ atmosphere.

\subsection{Kinetic analysis of $T G$ data}

We have recently discussed about the usefulness of the TG data in understanding the kinetics of the thermal decomposition [35]. Different methods are available for the extraction of activation energy from the analysis of TG data [36,37]. Our earlier studies [24,35] have shown that the Horowitz and Metzger method [38] gives consistent energy of activation $\left(E_{\mathrm{a}}\right)$ values for the polymer decomposition from the TG data of the doped and dedoped polymers in either air or in $\mathrm{N}_{2}$ atmosphere and hence this method is adopted in the present study. The method involves plotting double logarithm of the reciprocal of the weight fraction of the reactant versus temperature. A reference temperature $T_{\mathrm{s}}$ is defined such that $T=T_{\mathrm{s}}+\theta$ where $T_{\mathrm{s}}$ is experimental temperature when $\left(w / w_{0}\right)$ is equal to 0.368 for a first order reaction. $w_{0}$ is the initial weight and $w$ is the weight at temperature $T$. Using this approximation, the following equation is obtained:

$\ln \left(\ln \left(\frac{w_{0}}{w}\right)\right)=\left(\frac{E_{\mathrm{a}} \theta}{R T_{\mathrm{s}}^{2}}\right)$

Thus, a plot of $\ln \left(\ln \left(w_{0} / w\right)\right)$ against $\theta$ shows a straight line whose slope is $\left(E_{\mathrm{a}} / R T_{\mathrm{s}}^{2}\right)$.

Table 1 summarizes the activation energy values obtained from the kinetic analysis of the TG data of the four polymers. The values are higher in $\mathrm{N}_{2}$ atmosphere than in air.
The activation energy values of polyindole-5-carboxylic acid agree with those of polyindole (Fig. 14) supporting further our earlier inferences of decarboxylation. The second stage in the TG of polyindole-5-carboxylic acid corresponds to
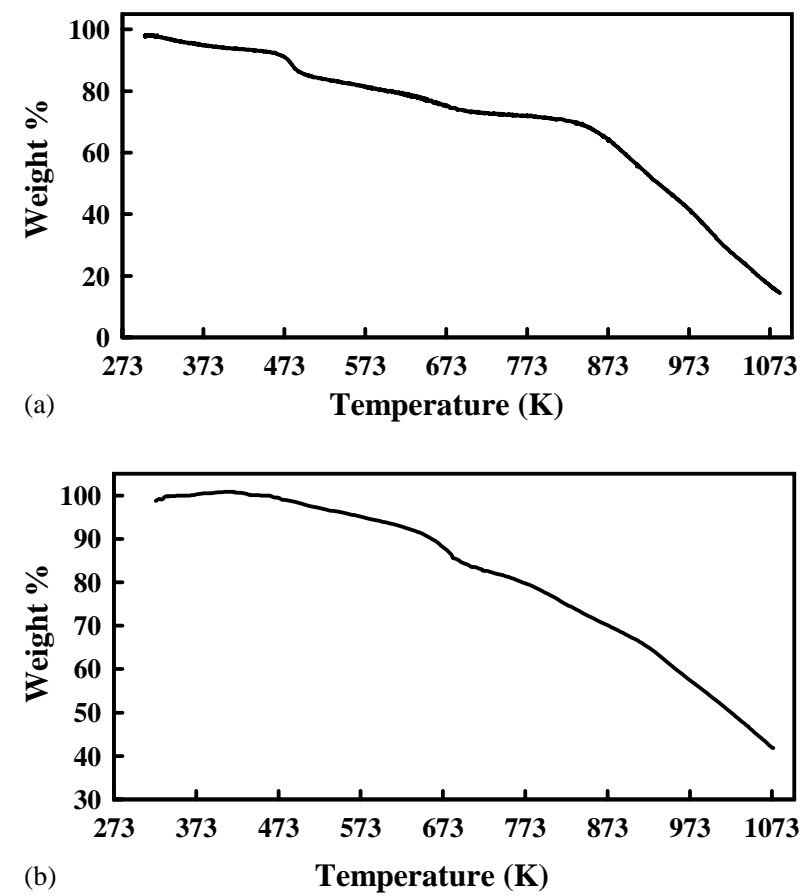

Fig. 11. TG curves of polycarbazole (a) doped and (b) dedoped in $\mathrm{N}_{2}$ atmosphere. 


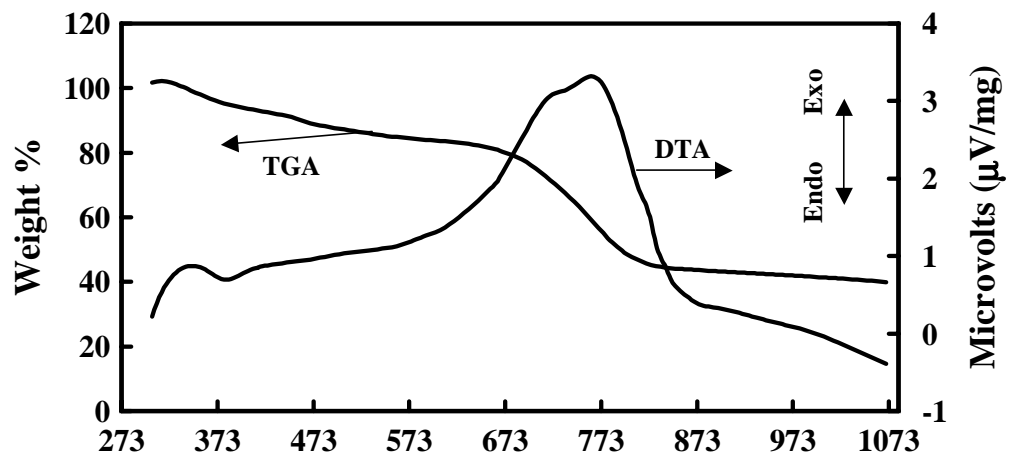

(a)

Temperature (K)

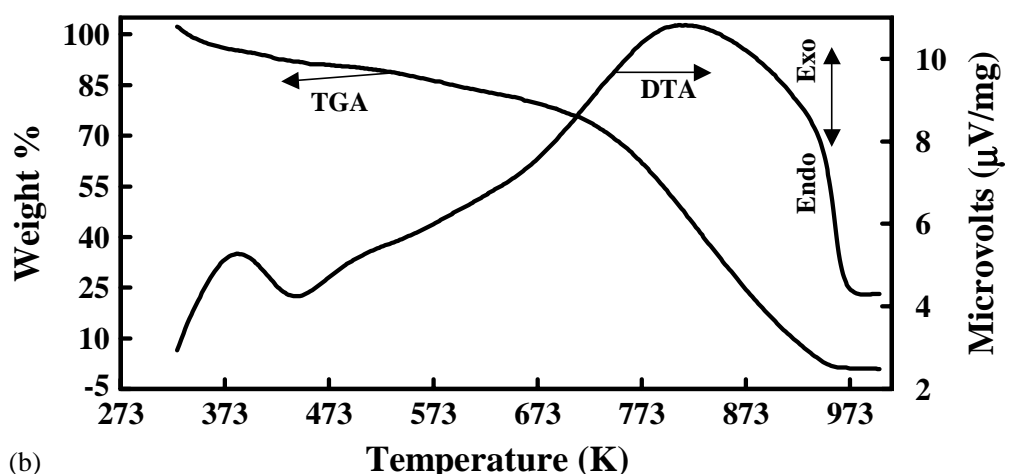

Fig. 12. TGA and DTA curves of poly( $N$-vinylcarbazole) (a) doped and (b) dedoped in air.

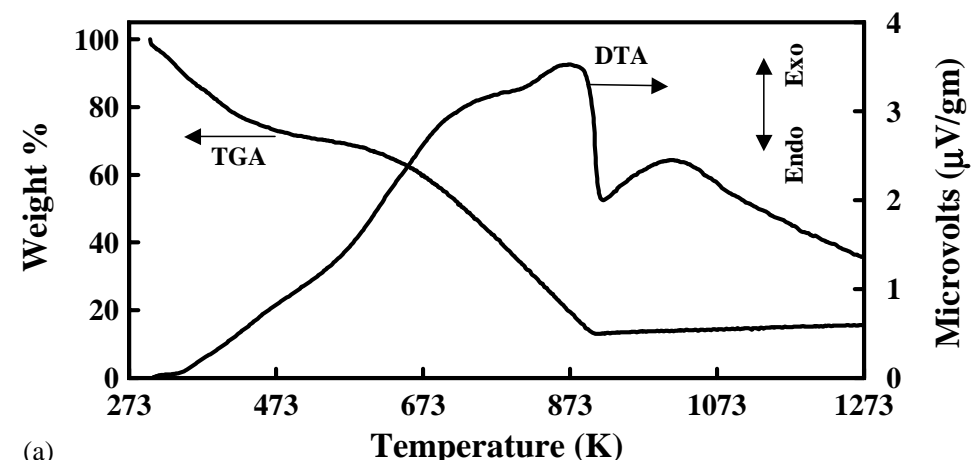

(a)

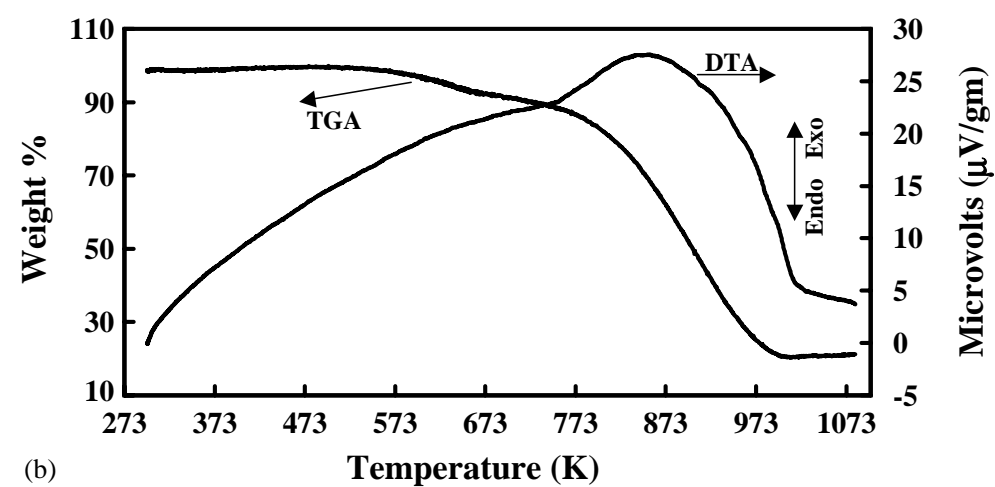

Fig. 13. TGA and DTA a curves of poly( $N$-vinylcarbazole) (a) doped and (b) dedoped in $\mathrm{N}_{2}$ atmosphere. 
Table 1

Comparison of thermal stability and activation energy $\left(E_{\mathrm{a}}\right)$ of the four polymers in air and $\mathrm{N}_{2}$ atmosphere

\begin{tabular}{|c|c|c|c|c|c|c|c|c|}
\hline \multirow[t]{3}{*}{ Polymer } & \multicolumn{4}{|c|}{$\begin{array}{l}\text { Temperature at which dedoped } \\
\text { polymer loses weight }(\mathrm{K})\end{array}$} & \multicolumn{4}{|c|}{$\begin{array}{l}\text { Activation energy }\left(E_{\mathrm{a}}\right) \text { by Horowitz and Metzger } \\
\text { method }\left(\mathrm{kJ} \mathrm{mol}^{-1}\right)\end{array}$} \\
\hline & \multicolumn{2}{|c|}{ Air $(\%)$} & \multicolumn{2}{|c|}{$\mathrm{N}_{2}(\%)$} & \multicolumn{2}{|l|}{ Air } & \multicolumn{2}{|l|}{$\mathrm{N}_{2}$} \\
\hline & 25 & 50 & 25 & 50 & Doped & Dedoped & Doped & Dedoped \\
\hline Polyindole & 719 & 817 & 700 & 955 & 45.4 & 49.7 & 66.4 & 66.8 \\
\hline Polyindole-5-carboxylic acid & 697 & 787 & 610 & 797 & - & 54.5 & - & 60.3 \\
\hline Polycarbazole & 839 & 947 & 823 & 1020 & 50.0 & 56.9 & 58.4 & 60.4 \\
\hline Poly $(N$-vinylcarbazole $)$ & 717 & 807 & 835 & 903 & 44.2 & 43.5 & 43.2 & 47.1 \\
\hline
\end{tabular}

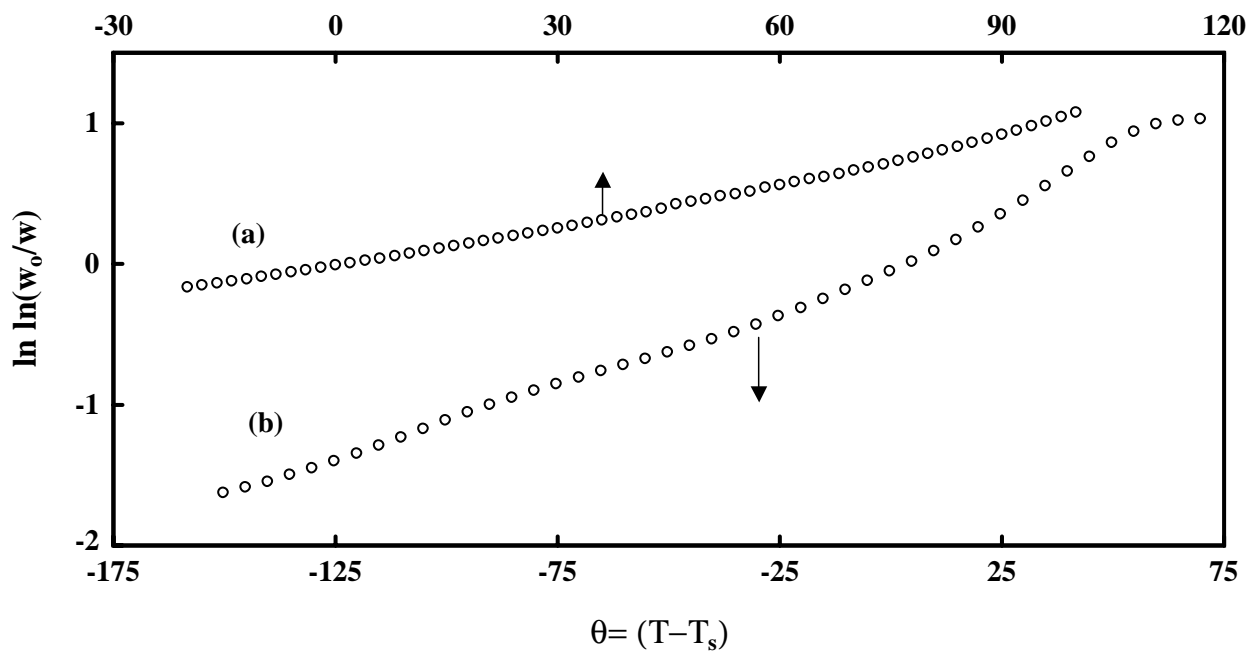

Fig. 14. Horowitz and Metzger plots of activation energy for: (a) dedoped polyindole $\left(T_{\mathrm{s}}=735 \mathrm{~K}\right)$; and (b) polyindole-5-carboxylic acid $\left(T_{\mathrm{s}}=733 \mathrm{~K}\right)$ in air.

the decomposition of polyindole backbone only. The activation energy values are somewhat higher for polycarbazole compared to poly $(N$-vinylcarbazole $)$. This result once again endorses the lower stability of poly $(N$-vinylcarbazole $)$ than polycarbazole.

\section{Conclusions}

1. The Arrhenius and Mott parameters obtained for the four polymers lead to the following inferences. The high activation energy values of polycarbazole and poly $(N$-vinylcarbazole) indicate that the intrinsic charge carriers are less at room temperature in these two polymers. This has led to the low conductivities for these two polymers. The larger $T_{\mathrm{O}}$ and $K_{\mathrm{O}}$ values for polyindole imply a short decay length and low density of states at the Fermi level. The conduction mechanism can be explained by 3D-variable range hopping in the cases of polyindole and polycarbazole and $1 \mathrm{D}$-variable range hopping for the self-doped polyindole-5-carboxylic acid. Poly( $N$-vinylcarbazole) shows nearest neighbour hopping conduction.

2. The thermal data are summarized in Table 1. It would be better to consider the thermal data obtained for the dedoped samples to ascertain the polymer decomposition temperature. The dopant elimination generally occurs between 373 and $573 \mathrm{~K}$. In the case of polyindole-5-carboxylicacid, decarboxylation is observed between 390 and $500 \mathrm{~K}$. On the basis of the results obtained for the loss of $50 \%$ weight in $\mathrm{N}_{2}$ atmosphere and also taking into consideration the kinetic analysis of the polymers, the following order of thermal stability can be arrived: polycarbazole > polyindole > $\operatorname{poly}(N$-vinylcarbazole $)>$ polyindole-5-carboxylic acid.

\section{Acknowledgements}

P. Syed Abthagir gratefully acknowledges the Council of Scientific and Industrial Research, New Delhi for the award of a Senior Research Fellowship. The help rendered by Dr. S. Sivakolunthu in recording some of the TGA/DTA data is also gratefully acknowledged.

\section{References}

[1] A.F. Diaz, K.K. Kanazawa, G.P. Gardini, J. Chem. Soc., Chem. Commun. (1979) 635. 
[2] G. Tourillon, F. Garnier, J. Electroanal. Chem. 135 (1982) 173.

[3] R.J. Waltman, J. Bargon, Can. J. Chem. 64 (1986) 173.

[4] F. Garnier, G. Tourillon, M. Gazard, J.C. Dubois, J. Electroanal. Chem. 148 (1983) 299.

[5] R.G. Linford (Ed.), Electrochemical Science and Technology of Polymers, vol. 2, Elsevier Applied Science, London, 1990.

[6] D.L. Wise, G.E. Wnek, D.J. Trantolo, T.M. Cooper, J.D. Gresser (Eds.), Electrical and Optical Polymer Systems: Fundamentals, Methods and Applications, Marcel Dekker, New York, 1998.

[7] V. Saxena, V. Shirodkar, R. Prakash, J. Solid State Electrochem. 4 (2000) 23.

[8] D. Sazou, Synth. Met. 130 (2002) 45.

[9] G. Safoula, K. Napo, J.C. Bernede, S. Touihri, K. Alimi, Eur. Polym. J. 37 (2001) 843.

[10] S.Y. Abe, J.C. Bernede, M.A. Delvalle, Y. Tregouet, F. Ragot, F.R. Diaz, S. Lefrant, Synth. Met. 126 (2002) 1.

[11] P. Chandrasekhar (Ed.), Conducting Polymers, Fundamentals and Applications: A Practical Approach, Kluwer Academic Publishers, The Netherlands, 1999.

[12] W.R. Salaneck, B. Liedberg, O. Inganas, R. Erlandsson, I. Lundstrom, A.G. MacDiarmid, M. Halpern, N.L.D. Somasiri, Mol. Cryst. Liq. Cryst. 121 (1985) 191.

[13] M. Probst, R. Holze, Electrochim. Acta 40 (1995) 213.

[14] T.L. Tansley, D.S. Maddision, J. Appl. Phys. 69 (1991) 7711.

[15] F. Mohammad, P.D. Calvert, N.C. Billingham, Bull. Electrochem. 10 (1994) 508.

[16] K. Sato, M. Yamaura, T. Hagiwara, Synth. Met. 40 (1991) 35.

[17] N.F. Mott, W.D. Twose, Adv. Phys. 10 (1961) 107.

[18] N.F. Mott, Adv. Phys. 16 (1967) 49.

[19] N.F. Mott, E.A. Davis, Electronic Processes in Non-Crystlline Materials, Clarendon Press, Oxford, 1979.

[20] K.M. Choi, C.Y. Kim, K.H. Kim, J. Phys. Chem. 96 (1992) 3782 .
[21] S.W. Kong, K.M. Choi, K.H. Kim, J. Phys. Chem. Solids 53 (1992) 657.

[22] K.M. Choi, J.H. Jang, K.H. Kim, Mol. Cryst. Liq. Cryst. 220 (1992) 201.

[23] M. Satoh, K. Kaneto, K. Yoshino, Synth. Met. 14 (1986) 289.

[24] P. Syed Abthagir, K. Dhanalakshmi, R. Saraswathi, Synth. Met. 93 (1998) 1.

[25] E.B. Mano, B.A.L. Calafate, J. Polym. Sci., Polym. Chem. Ed. 21 (1983) 829

[26] S.A. Jenekhe, S.T. Wellinghoff, J.F. Reed, Mol. Cryst. Liq. Cryst. 105 (1984) 175

[27] S. Touihri, G. Safoula, J.C. Bernede, K. Alimi, Thin Solid Films 304 (1997) 16.

[28] J.G. Mackintosh, C.R. Redpath, A.C. Jones, P.R.R.L. Smith, D. Reed, A.R. Mount, J. Electroanal. Chem. 375 (1994) 163.

[29] H. Talbi, D. Billaud, G. Louarn, A. Pron, Spectrochim. Acta Part A: Mol. Biomol. Spectrosc. 57 (2001) 423.

[30] K. Jackowska, A. Kudelski, Buckowska, Electrochim. Acta 39 (1994) 1365.

[31] J.G. Mackintosh, A.R. Mount, J. Chem. Soc., Faraday Trans. 90 (1994) 1121.

[32] J.G. Mackintosh, C.R. Redpath, A.C. Jones, R.R. Langridge-Smith, A.R. Mount, J. Electroanal. Chem. 388 (1995) 179.

[33] K. Dhanalakshmi, R. Saraswathi, J. Mater. Sci. 36 (2001) 4107.

[34] M.A.S. Abdou, S. Holdcroft, in: H.S. Nalwa (Ed.), Handbook of Organic Conductive Molecules and Polymers, vol. 2, Wiley, NY, 1997 (Chapter 20).

[35] P. Syed Abthagir, R. Saraswathi, S. Sivakolunthu, Thermochim. Acta 411 (2004) 109.

[36] J. Sestak, J. Therm. Anal. 16 (1979) 503

[37] K. Celis, I. Van Driessche, R. Mouton, G. Vanhoyland, S. Hoste, Meas. Sci. Rev. 1 (2001) 177.

[38] H.H. Horowitz, G. Metzger, Anal. Chem. 35 (1963) 1464 